OPEN ACCESS

Edited by:

Yang Yang,

Northwest University, China

Reviewed by:

Suowen Xu,

University of Rochester, United States

Bin Geng,

Fu Wai Hospital, China

Boon-Seng Wong,

Singapore Institute of Technology,

Singapore

*Correspondence:

Ulkan Kilic

uckili@@yahoo.com

Specialty section

This article was submitted to Cellular Endocrinology,

a section of the journal

Frontiers in Endocrinology

Received: 31 July 2018 Accepted: 27 September 2018

Published: 15 October 2018

Citation:

Elibol B and Kilic U (2018) High Levels of SIRT1 Expression as a Protective Mechanism Against Disease-Related Conditions. Front. Endocrinol. 9:614. doi: 10.3389/fendo.2018.00614

\section{High Levels of SIRT1 Expression as a Protective Mechanism Against Disease-Related Conditions}

\author{
Birsen Elibol ${ }^{1}$ and Ulkan Kilic ${ }^{2 *}$ \\ ${ }^{1}$ Department of Medical Biology, Faculty of Medicine, Bezmialem Vakif University, Istanbul, Turkey, ${ }^{2}$ Department of Medical \\ Biology, Faculty of Medicine, University of Health Sciences, Istanbul, Turkey
}

SIRT1 protein, a member of Silent Information Regulator 2 (Sir2) protein family, have gained considerable attention as epigenetic regulators for a great area in the human physiology. Changes in sirtuin expression are critical in several diseases, including metabolic syndrome, cardiovascular diseases, cancer and neurodegeneration. Here, we provide an overview of the association of the increasing level of SIRT1 protein for regulating some disease related conditions such as obesity, cardiovascular diseases and neurodegeneration. This review also provides a detailed molecular understanding of the interaction of the some basic molecules with increasing SIRT1 levels rather than reduction of the SIRT1 expression. In this context, the current approaches to enhancing the expression of SIRT1 points the importance of epigenetics in several age-related diseases to provide a healthy aging by developing novel therapies which can prevent or damp the progression of some diseases.

Keywords: SIRT1 expression, oxidative stress, metabolic diseases, cardiovascular diseases, neurodegenerative diseases

\section{INTRODUCTION}

Sirtuin 1 (SIRT1) which is encoded by the SIRT1 gene is the most conserved mammalian nicotinamide adenine dinucleotide (NAD+) dependent histone deacetylase (1). Besides its role being a target for histone and non-histone proteins, SIRT1 functions as a transcription factor for many different physiological processes (2). According to the previous experiments which were performed using yeast, worms and flies as model organisms, sirtuins were accepted as evolutionarily conserved epigenetic mediators of longevity (3-5). In addition to the key role on extending life by regulating the response to some conditions such as fasting, caloric restriction and exercise, SIRT1 regulates many endocrine functions, protects organism from oxidative stress-related cellular events, promotes DNA stability, and decreases various age-related disorders, such as neurodegenerative disease, metabolic abnormalities, and cancer (6-9).

SIRT1 protein is expressed in most of the body parts including brain, heart, kidney, liver, pancreas, spleen, skeletal muscle, endothelial tissue and white adipose tissue. By expression and activation of SIRT1, modulation of its downstream pathways occurs by targeting several cellular proteins, such as nuclear factor kappa-light-chain-enhancer of activated B cells (NF$\kappa B)$, peroxisome proliferators-activated receptor-gamma (PPAR- $\gamma$ ) and its coactivator peroxisome proliferator-activated receptor gamma coactivator 1-alpha (PGC-1 $\alpha$ ), protein tyrosine phosphatase (PTP), forkhead transcriptional factors (the FoxO subgroup), adenosine monophosphate activated protein kinase (AMPK), CRE-binding protein regulated transcription coactivator 2 (CRTC2), 
endothelial nitric oxide synthase (eNOS), p53, myogenic differentiation (MyoD), liver X receptor (LXR), and transcription factor E2F1 $(10,11)$. Through its deacetylation activity, SIRT1 modulates functions of these critical molecules and shows its critical and multifaceted roles in cellular physiology (Figure 1).

Alterations of the level of SIRT1 expression were determined in several diseases including metabolic diseases, neurodegenerative diseases, cancer and aging. Whereas an increase in the expression of the SIRT1 protein was observed in cancer $(12,13)$, reductions in the SIRT1 level was more common in other diseases such as Alzheimer's Diseases (AD), Parkinson Disease (PD), obesity, diabetes, and cardiovascular diseases (14-18). Recent developments elucidated the relation between downregulation of SIRT1 levels and disease progression as an increase in the oxidative stress and inflammation $(16,17)$. For example, due to a significant decrease in SIRT1 levels which correlated with an increase in the oxidative stress parameters, accumulation of Tau proteins in $\mathrm{AD}$, enhancement of acetylated p53 expression levels in coronary artery disease and increase in the fatty acid oxidation in obesity were observed in the patients $(15,17,19,20)$.

Previous studies showed that SIRT1 overexpression significantly increased cell viability, decreased cell apoptosis and reduced the release of pro-inflammatory cytokines (21-24). In addition, the regulation of metabolism and longevity by SIRT1 occurs through controlling the maturation of hypothalamic peptide hormones $(25,26)$. Specificity for SIRT1 increases in the relevant metabolic pathways in the hypothalamic circuitries which is also associated with altered downstream factors of SIRT1 such as FoxO transcription factors $(27,28)$. In the light of this information, we reviewed recent findings related to the association of the increasing level of SIRT1 protein rather than reduction of the SIRT1 expression and regulation of some disease related conditions such as obesity, cardiovascular diseases and neurodegeneration. The overarching aim of this paper is to provide a basis for hypothesizing that the level of SIRT1 are mechanistically increased to overcome the dysfunction of SIRT1 activity in the diseased conditions.

\section{SIRT1 AND METABOLIC DISEASES}

SIRT1 protein protects the functions of adipose tissue and liver in several aspects $(29,30)$ such as glucose homeostasis and fat metabolism against severe obesity $(31,32)$. It is also involved in energy balance and stress. Insulin sensitivity is increased in the pancreatic beta cells which have insulin resistance due to overexpression of $\operatorname{SIRT} 1(30,33)$. The activity of $\operatorname{PPAR} \gamma$ which have a role in the storage of glucose and fatty acid in adipose tissue is repressed by SIRT1 (34). During short term fasting, the CRTC2 is also depressed by SIRT1 and thus gluconeogenesis is declined in the liver tissue. During long term fasting, SIRT1 expression deacetylates and activates the PGC- $1 \alpha$ to decrease adiposity and lipogenesis and to increase fatty acid oxidation (3537). In addition, SIRT1 deacetlylates sterol regulatory element binding protein (SREBP), farnesoid X receptor (FXR), as well as liver $\mathrm{X}$ receptor (LXR) to increase bile acid production and to reverse cholesterol transport $(30,38)$. Thus, SIRT1 can be called as a "Master Metabolic Regulator" (30). Indeed, the dysregulation of energy sensing may cause inflammation and insulin resistance. Because of prevention of pro-inflammatory responses, SIRT1 behaves as a positive regulator of insulin in the adipose tissue (39). In one of the recent study, after feeding with high dietary fructose, the liver of rats were investigated in response to SIRT1 expression as a main energy sensing protein (40). However, they demonstrated a significant increase in the SIRT1 expression in the fructose-induced inflammation suggesting compensatory rise in the level of SIRT1 to decline the inflammation-related metabolic reactions (40). In addition, overexpression of SIRT1 in obesity which was formed by high-fat diet protects lipidinduced inflammation and hepatic steatosis while providing better glucose tolerance (41). These favorable effects of SIRT1 may be related with the activation of the antioxidant enzymes and stimulation of PGC1 $\alpha$ to decrease the level of pro-inflammatory cytokines (41).

In some neurodegenerative diseases, a number of neuropeptide systems in the hypothalamus are affected from activity of SIRT1 which indicate an impact on metabolism. For example, SIRT1 upregulates the level of orexin receptor specifically in the lateral hypothalamic area and the ventromedial nucleus of the hypothalamus, whereas the expression of orexin and melanin-concentrating hormone is reduced in the hypothalamus due to inhibition of the active state of orexin neurons $(25,42,43)$. In addition, SIRT1 also regulates the expression of BDNF in the brain. It was found that increased SIRT1 level diminished BDNF signaling which resulted in severe hyperphagia and obesity both in humans and animals $(44,45)$. These results showed that compensatory increase in the SIRT1 level to cope with the disease outcomes such as oxidative stress brings some additional metabolic dysfunctions in the body due to altered peptides in the endocrine system.

In addition to the obesity, SIRT1 has a role in the hepatic energy metabolism by modulating it nutritionally and hormonally. This modulation is mostly occurred through the deacetylation of metabolic regulators (46). Previous studies also showed that obese patients with non-alcoholic fatty-liver disease (NAFLD), which is the most common liver disease caused by elevated hepatic lipids, inflammation and oxidative stress, had high plasma levels of SIRT1 producing a potential against the physiological mechanisms related to NAFLD (47). In this type of disease, the action mechanism of SIRT1 acted through the modulation of PPAR $\alpha$ activity and fatty acid oxidation (48).

On the other hand, it was found that increase in the SIRT1 activity upregulates genes-related metabolic functions, promotes insulin sensitivity and reduces inflammatory gene expressions in the adipose tissue of diet-induced obese animals (49). In addition, we found a polymorphism in the promoter region of SIRT1 gene in obese children drawing attention to the association between altered SIRT1 activity and the risk of obesity (50). Previous reports also showed the protective role of SIRT1 on the development of osteoarthritis by upregulation of cartilage extracellular matrix genes and downregulation of matrix-degrading enzymes $(51,52)$. In addition, increase in the SIRT1 activity had a protective effect against osteoarthritis in 


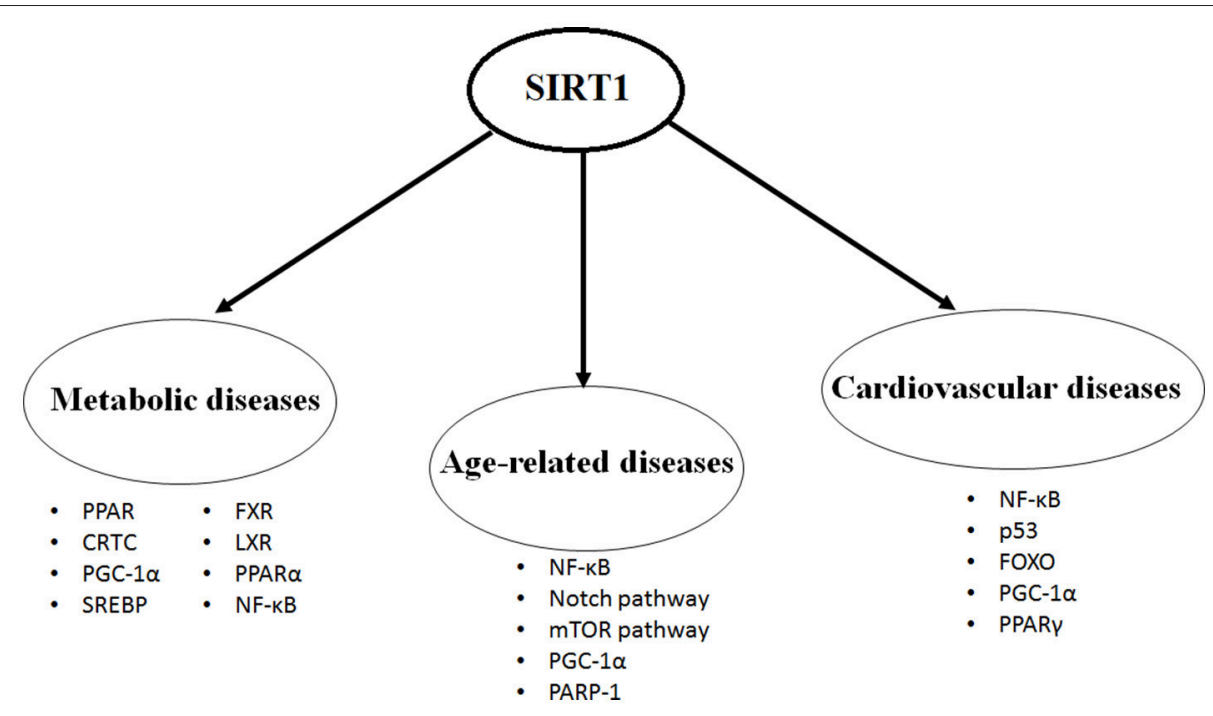

FIGURE 1 | The most studied targets of SIRT1 in the metabolic diseases, age-related diseases and cardiovascular diseases.

animal models $(53,54)$. Therefore, the investigators suggested that the increase both in the activity and expression of SIRT1 might be a protective strategy for progression of osteoarthritis via the modulation of the NF- $\kappa$ B pathway (55).

\section{SIRT1 AND AGE-RELATED NEURODEGENERATIVE DISEASES}

The relationships between SIRT1 and age were investigated in the previous studies related to interaction of lifespan elongation and calorie restriction which is thought as an enhancer for SIRT1 activity $(56,57)$. Most of these studies showed that calorie intake restriction innervates the extension of life by the inducement of defense of cells against to free radicals and toxins for attenuation of apoptosis or amelioration of cell repair which are desired factors in aging (58-60). That means, altered SIRT1 expression and activity is thought to be a potent way to keep the cells and organs properly functioning for longer times. The positive correlation between age and SIRT1 expression and/or activity may be a compensation against unexpected situations such as oxidative stress $(61,62)$. For example, in one of our previous study, it was noted higher level of SIRT1 protein in older people compared with the SIRT1 level in the younger people (62). It was thought that increased protein level of SIRT1 in older people may be a compensatory mechanism due to accumulation of oxidative stress-related products and elimination of antioxidant enzyme level in elderly (62). However, increase in the expression does not mean increase in the activity of protein. An oxidative stressdependent decrease in the SIRT1 activity was noted in aged animals that had high levels of SIRT1 protein $(63,64)$. The decline in the activity of SIRT1 may not be related directly with SIRT1 protein but also its downstream or upstream molecules such as a decline in NAD+ levels with aging (65).
One of the main risk factor for several neurodegenerative diseases such as Alzheimer's disease (AD) and Parkinson's disease $(\mathrm{PD})$ is age. The common underlying mechanisms of neurodegeneration are increase in the neuroinflammation, mitochondrial damages and oxidative stress $(66,67)$. In literature, it was shown that sirtuins' hyperactivity could reduce these negative outcomes both in vivo and in vitro due to its neuroprotective role (68-71). In the AD pathology, SIRT1 deacetylates substrates in favor of the non-amyloidogenic pathway or acts directly on the $\mathrm{A} \beta$ and Tau proteins (72). Molecular studies showed that SIRT1 activation prevents the accumulation of $\mathrm{A} \beta$ plaques and tau pathology through the $\mathrm{NF}-\kappa \mathrm{B}$ signaling pathway by upregulation of the ADAM10 gene, induction of the Notch pathway, and inhibition of the mTOR pathway $(20,73,74)$. As shown in previous studies, SIRT1 epigenetically reprograms inflammation taking about $\mathrm{AD}$ formation at the earlier stages by altering transcription factors $(24,75,76)$. In addition, it was observed that brains of $\mathrm{AD}$ patients have consistently reduced NAD+ levels and SIRT1 transcription and/or protein levels involved in chronic inflammation that can also be altered by increased levels of the activated proinflammatory transcription factor NF-кB (77-79). In one of our studies, we found a significant increase in the SIRT1 level of dementia patients (80). Furthermore, in the patients with Huntington's disease (HD), Baldo and his colleagues found higher expression of SIRT1 protein level in the most affected brain regions, especially hypothalamic regions important for metabolic regulation, compared to brain regions which were less affected from the mutant huntingtin protein (28). In PD, SIRT1 inhibits $\alpha$-synuclein aggregation by deacetylating proteins such as heat shock proteins and PGC- $1 \alpha$ and, therefore, it protects dopaminergic neurons against cell death which occur due to the formation of insoluble fibrils called Lewy bodies $(81,82)$. In the in vitro $\mathrm{PD}$ model, it was observed that an overexpression of SIRT1 due to application of toxin (rotenone or MPTP) which 
causes neurodegeneration was rescued cells from oxidative stress $(16,83)$. The neuroprotection against to PD occurred by the mechanism of decreasing in the expression of NF- $\kappa \mathrm{B}$ and cleaved PARP-1. In a postmortem study, the levels of SIRT1 showed a slight increase in the dementia patients with Lewy bodies $(16,83)$. However, as seen in the $\mathrm{AD}$, the activity of the SIRT1 protein also decreased in the $\mathrm{PD}$ patients producing neurodegeneration in correlation with possible higher oxidative stress, synaptic and cell loss, and neuroinflammation (16).

We thought that the high levels of SIRT1 protein might have a role in alleviating the oxidative stress that is significantly increased in neurodegeneration because an induction of the SIRT1 expression occurs when the organism encounters a biological stress such as aging or an age-related disorder due to the role function of SIRT1 as an important stress sensor molecule.

Also, in literature, it was stated that high levels of SIRT1 may increase the expression of genes related to neuronal protection (84-86). On the other hand, SIRT1 behaves as a double edged sword in response to inflammation which is a cause of neurodegeneration. That means, low levels of SIRT1 cause early acute inflammation-related damages to tissues by increasing NF-kB, and high levels of SIRT1 during late inflammation cause immunosuppression and increased the rate of death (87). In a previous study, investigators observed that increase in the expression level of SIRT1 cannot protect the brain from neurodegeneration without increasing the activity level of SIRT1. For example, Ciriello and his colleagues observed a significant decrease in the level of phosphorylated SIRT1, the active form of SIRT1, in the patients with multiple sclerosis (88). Interestingly, a significant negative correlation between phosphorylated and non-phosphorylated forms of SIRT1 was observed explaining both the SIRT1 overexpression and inactivity of SIRT1 in diseased state. In addition, when a SIRT1-activating molecules were given to the organisms, profound therapeutic benefits and neuroprotective effects were recorded against age-dependent neurodegenerative diseases (89).

\section{SIRT1 AND CARDIOVASCULAR DISEASE}

Nowadays, the sirtuin protein family is thought as one of the important target for cardiovascular diseases (CVD). Therefore, the role of SIRT1 protein and its downstream molecules also gains importance in the experimental studies related with CVD development. In cardiomyocytes, during prenatal period, SIRT1 is found in the nucleus, however, it is mostly located in the cytoplasm of myocytes of adult heart of rodents (90). Previously, we found that the level of the SIRT1 expression was significantly higher in the CVD patients compared to the levels of SIRT1 in healthy subjects pointing the crosstalk between SIRT1 protein expression and reactive oxygen species (61). In this previous study, we also found a significant increase in the oxidative stress parameters which may be an inducer for SIRT1 expression. In cardiomyocytes, myoblast gains resistance against to oxidative stress by increasing expression of nuclear SIRT1 protein. To do produce this antioxidative activity, SIRT1 protein enhances the level of MnSOD expression through p53 deacetylation (90). In addition, activation of FoxO1dependent oxidative pathway by overexpression of SIRT1 protein is another regulatory way of protection of cardiomyocytes from oxidative stress (91). By the help of this pathway, cardiac infarct volume is reduced to ameliorate and recover cardiac function after ischemia/reperfusion in mice (92). It is also thought that transcriptional activity of NF- $\kappa \mathrm{B}$ protein, a preconditioner in cardiac ischemia, is inhibited by SIRT1 protein to promote cell protection $(93,94)$. In literature, it was reported that the activity of SIRT1 protein is directly or indirectly controlled via the JNK1SIRT1 link by accumulated oxidative stress which is caused by an increase in the ROS level due to aging or age-related diseases enzyme (1). It was demonstrated that ROS inhibited JNK phosphatases which activated the JNK1 to phosphorylate SIRT1 $(95,96)$. Furthermore, this phosphorylation increased the activity of SIRT1 resulting its translocation into the nuclei (97). Alcendor et al. (91) noted that the rate of SIRT1 overexpression had two-sided action in the cardiovascular system. For example, 2.5- to 7.5-fold increase in the SIRT1 expression attenuated apoptosis, the symptoms of cardiac dysfunction, age-related cardiac hypertrophy and expression of senescence markers. On the other side, 12.5-fold increase in the expression of SIRT1 resulted in increased cardiac hypertrophy due to oxidative stress and apoptosis. This study explained clearly the relation between oxidative stress and overexpression of SIRT1 to the pathological levels in CVD patients. In one of our previous studies (61), we found a positive correlation between total antioxidant level and SIRT1 level in CVD patients. Therefore, we can conclude that the increase in the SIRT1 level may be a compensatory mechanism to increase the antioxidants against oxidative stress in CVD patients.

Contrary to some previous studies $(98,99)$, the SIRT1 level significantly decreased approaching to control values in the CVD patients receiving statin therapy (100). The decline in the SIRT1 level by statins can be explained by the statins' inducement effect on PPAR $\gamma$ activity to protect patients against the progression of atherosclerosis (101). On the other hand, PPAR $\gamma$ inhibits SIRT1 expression at the transcriptional level which interrupting compensatory action of increased SIRT1 expression (102).

\section{CONCLUSION}

Recent studies have shown that age-related diseases or endocrine system dysfunctions are associated with an increase in SIRT1 expression levels, but with a decrease in their activity. The oxidative stress produced during these processes may lead to compensatory or protective increase in the SIRT1 expression to deal with the decline of the SIRT1 activity.

\section{AUTHOR CONTRIBUTIONS}

BE wrote the draft of the manuscript and UK finalized the manuscript. 


\section{REFERENCES}

1. Salminen A, Kaarniranta K, Kauppinen A. Crosstalk between oxidative stress and SIRT1: impact on the aging process. Int J Mol Sci. (2013) 14:3834-59. doi: 10.3390/ijms14023834

2. Yamamoto $\mathrm{H}$, Schoonjans $\mathrm{K}$, Auwerx J. Sirtuin functions in health and disease. Mol Endocrinol. (2007) 21:1745-55. doi: 10.1210/me.2007-0079

3. Rogina B, Helfand SL. Sir2 mediates longevity in the fly through a pathway related to calorie restriction. Proc Natl Acad Sci USA. (2004) 101:15998-6003. doi: 10.1073/pnas.0404184101

4. Tissenbaum HA, Guarente L. Increased dosage of a sir-2 gene extends lifespan in Caenorhabditis elegans. Nature (2001) 410:227-30. doi: $10.1038 / 35065638$

5. Kaeberlein M, McVey M, Guarente L. The SIR2/3/4 complex and SIR2 alone promote longevity in Saccharomyces cerevisiae by two different mechanisms. Genes Dev. (1999) 13:2570-80. doi: 10.1101/gad.13.19.2570

6. Guarente L, Franklin H. Epstein lecture: sirtuins, aging, and medicine. NEngl J Med. (2011) 364:2235-44. doi: 10.1056/NEJMra1100831

7. Longo VD, Kennedy BK. Sirtuins in aging and age-related disease. Cell (2006) 126:257-68. doi: 10.1016/j.cell.2006.07.002

8. Koubova J, Guarente L. How does calorie restriction work? Genes Dev. (2003) 17:313-21. doi: 10.1101/gad.1052903

9. Jeśko H, Wencel P, Strosznajder RP, Strosznajder JB. Sirtuins and their roles in brain aging and neurodegenerative disorders. Neurochem. Res. (2017) 42:876-90. doi: 10.1007/s11064-016-2110-y

10. Valle I, Alvarez-Barrientos A, Arza E, Lamas S, Monsalve M. PGC1alpha regulates the mitochondrial antioxidant defense system in vascular endothelial cells. Cardiovasc Res. (2005) 66:562-73. doi: 10.1016/j.cardiores.2005.01.026

11. Olmos Y, Brosens JJ, Lam EW. Interplay between SIRT proteins and tumour suppressor transcription factors in chemotherapeutic resistance of cancer. Drug Resist Update (2011) 14:35-44. doi: 10.1016/j.drup.2010.12.001

12. Chen WY, Wang DH, Yen RC, Luo J, Gu W, Baylin SB. Tumor suppressor HIC1 directly regulates SIRT1 to modulate p53-dependent DNA-damage responses. Cell (2005) 123:437-48. doi: 10.1016/j.cell.2005.08.011

13. Wang C, Chen L, Hou X, Li Z, Kabra N, Ma Y, et al. Interactions between E2F1 and SirT1 regulate apoptotic response to DNA damage. Nat Cell Biol. (2006) 8:1025-31. doi: 10.1038/ncb1468

14. Lutz MI, Milenkovic I, Regelsberger G, Kovacs GG. Distinct patterns of sirtuin expression during progression of Alzheimer's disease. Neuromol Med. (2014) 16:405-14. doi: 10.1007/s12017-014-8288-8

15. Costa Cdos S, Hammes TO, Rohden F, Margis R, Bortolotto JW, Padoin AV, et al. SIRT1 transcription is decreased in visceral adipose tissue of morbidly obese patients with severe hepatic steatosis. Obes Surg. (2010) 20:633-9. doi: 10.1007/s11695-009-0052-z

16. Singh P, Hanson PS, Morris CM. SIRT1 ameliorates oxidative stress induced neural cell death and is down-regulated in Parkinson's disease. BMC Neurosci. (2017) 18:46. doi: 10.1186/s12868-017-0364-1

17. Chan SH, Hung CH, Shih JY, Chu PM, Cheng YH, Lin HC, et al. SIRT1 inhibition causes oxidative stress and inflammation in patients with coronary artery disease. Redox Biol. (2017) 13:301-9. doi: 10.1016/j.redox.2017. 05.027

18. Aditya R, Kiran AR, Varma DS, Vemuri R, Gundamaraju R. A Review on SIRtuins in Diabetes. Curr Pharm Des. (2017) 23:2299-307. doi: 10.2174/1381612823666170125153334

19. Julien C, Tremblay C, Emond V, Lebbadi M, Salem N Jr, Bennett $\mathrm{DA}$, et al. Sirtuin 1 reduction parallels the accumulation of tau in Alzheimer disease. J Neuropathol Exp Neurol. (2009) 68:48-58. doi: 10.1097/NEN.0b013e3181922348

20. Braidy N, Jayasena T, Poljak A, Sachdev PS. Sirtuins in cognitive ageing and Alzheimer's disease. Curr Opin Psychiatry (2012) 25:226-30. doi: 10.1097/YCO.0b013e32835112c1

21. Li K, Lv G, Pan L. Sirtl alleviates LPS induced inflammation of periodontal ligament fibroblasts via downregulation of TLR4. Int J Biol Macromol. (2018) 119:249-54. doi: 10.1016/j.ijbiomac.2018.07.099

22. Yang SR, Wright J, Bauter M, Seweryniak K, Kode A, Rahman I. Sirtuin regulates cigarette smoke-induced proinflammatory mediator release via RelA/p65 NF-kappaB in macrophages in vitro and in rat lungs in vivo: implications for chronic inflammation and aging. Am J Physiol Lung Cell Mol Physiol. (2007) 292:L567-76. doi: 10.1152/ajplung.00308.2006

23. Rajendrasozhan S, Yang SR, Kinnula VL, Rahman I. SIRT1, an antiinflammatory and antiaging protein, is decreased in lungs of patients with chronic obstructive pulmonary disease. Am J Respir Crit Care Med. (2008) 177:861-70. doi: 10.1164/rccm.200708-1269OC

24. Yeung F, Hoberg JE, Ramsey CS, Keller MD, Jones DR, Frye RA, et al. Modulation of NF-kappaB-dependent transcription and cell survival by the SIRT1 deacetylase. EMBO J. (2004) 23:2369-80. doi: 10.1038/sj.emboj.7600244

25. Satoh A, Brace CS, Ben-Josef G, West T, Wozniak DF, Holtzman DM, et al. SIRT1 promotes the central adaptive response to diet restriction through activation of the dorsomedial and lateral nuclei of the hypothalamus. $J$ Neurosci. (2010) 30:10220-32. doi: 10.1523/JNEUROSCI.1385-10.2010

26. Nillni EA. The metabolic sensor Sirtl and the hypothalamus: interplay between peptide hormones and pro-hormone convertases. Mol Cell Endocrinol. (2016) 438:77-88 doi: 10.1016/j.mce.2016.09.002

27. Parker JA, Vazquez-Manrique RP, Tourette C, Farina F, Offner N, Mukhopadhyay A, et al. Integration of beta-catenin, sirtuin, and FOXO signaling protects from mutant huntingtin toxicity. J Neurosci (2012) 32:12630-40. doi: 10.1523/JNEUROSCI.0277-12.2012

28. Baldo B, Gabery S, Soylu-Kucharz R, Cheong RY, Henningsen JB, Englund E, et al. SIRT1 is increased in affected brain regions and hypothalamic metabolic pathways are altered in Huntington disease. Neuropathol Appl Neurobiol. (2018) doi: 10.1111/nan.12514. [Epub ahead of print]

29. Pedersen SB, Ølholm J, Paulsen SK, Bennetzen MF, Richelsen B. Low Sirt1 expression, which is upregulated by fasting, in human adipose tissue from obese women. Int J Obes. (2008) 32:1250-5. doi: 10.1038/ijo.2008.78

30. Schug TT, Li X. Sirtuin 1 in lipid metabolism and obesity. Ann Med. (2011) 43:198-211. doi: 10.3109/07853890.2010.547211

31. Li X. SIRT1 and energy metabolism. Acta Biochim Biophys Sin (Shanghai) (2013) 45:51-60. doi: 10.1093/abbs/gms108

32. Cakir I, Perello M, Lansari O, Messier NJ, Vaslet CA, Nillni EA. Hypothalamic Sirtl regulates food intake in a rodent model system. PLoS ONE (2009) 4:e8322. doi: 10.1371/journal.pone.0008322

33. Banks AS, Kon N, Knight C, Matsumoto M, Gutiérrez-Juárez R, Rossetti L, et al. SirT1 gain of function increases energy efficiency and prevents diabetes in mice. Cell Metab. (2008) 8:333-41. doi: 10.1016/j.cmet.2008.08.014

34. Picard F, Kurtev M, Chung N, Topark-Ngarm A, Senawong T, Machado De Oliveira R, et al. Sirt1 promotes fat mobilization in white adipocytes by repressing PPAR-gamma. Nature (2004) 429:771-6. doi: $10.1038 /$ nature 02583

35. Nemoto S, Fergusson MM, Finkel T. SIRT1 functionally interacts with the metabolic regulator and transcriptional coactivator PGC-1 $\alpha$. J Biol Chem. (2005) 280:16456-60. doi: 10.1074/jbc.M501485200

36. Purushotham A, Schug TT, Xu Q, Surapureddi S, Guo X, Li X. Hepatocyte-specific deletion of SIRT1 alters fatty acid metabolism and results in hepatic steatosis and inflammation. Cell Metab. (2009) 9:327-38. doi: 10.1016/j.cmet.2009.02.006

37. Rodgers JT, Lerin C, Haas W. Nutrient control of glucose homeostasis through a complex of PGC-1alpha and SIRT1. Nature (2005) 434:113-8. doi: $10.1038 /$ nature 03354

38. Li X, Zhang S, Blander G. SIRT1 deacetylates and positively regulates the nuclear receptor LXR. Mol Cell (2007) 28:91-106. doi: 10.1016/j.molcel.2007.07.032

39. Alageel A, Tomasi J, Tersigni C, Brietzke E, Zuckerman H, Subramaniapillai $\mathrm{M}$, et al. Evidence supporting a mechanistic role of sirtuins in mood and metabolic disorders. Prog Neuropsychopharmacol Biol Psychiatry (2018) 86:95-101. doi: 10.1016/j.pnpbp.2018.05.017

40. Veličković N, Teofilović A, Ilić D, Djordjevic A, Vojnović Milutinović D, Petrović S, et al. Modulation of hepatic inflammation and energy-sensing pathways in the rat liver by high-fructose diet and chronic stress. Eur J Nutr. (2018). doi: 10.1007/s00394-018-1730-1. [Epub ahead of print].

41. Pfluger PT, Herranz D, Velasco-Miguel S, Serrano M, Tschöp MH. Sirt1 protects against high-fat diet-induced metabolic damage. Proc Natl Acad Sci USA. (2008) 105:9793-8. doi: 10.1073/pnas.0802917105

42. Froy O, Sherman H, Bhargava G, Chapnik N, Cohen R, Gutman R, et al. Spontaneous caloric restriction associated with increased leptin levels 
in obesity-resistant alphaMUPA mice. Int J Obes (Lond) (2011) 35:226-35. doi: 10.1038/ijo.2010.125

43. Hayakawa K, Hirosawa M, Tabei Y, Arai D, Tanaka S, Murakami N, et al. Epigenetic switching by the metabolism-sensing factors in the generation of orexin neurons from mouse embryonic stem cells. J Biol Chem. (2013) 288:17099-110. doi: 10.1074/jbc.M113.455899

44. Unger TJ, Calderon GA, Bradley LC, Sena-Esteves M, Rios M. Selective deletion of Bdnf in the ventromedial and dorsomedial hypothalamus of adult mice results in hyperphagic behavior and obesity. J Neurosci. (2007) 27:14265-74. doi: 10.1523/JNEUROSCI.3308-07.2007

45. Cordeira JW, Felsted JA, Teillon S, Daftary S, Panessiti M, Wirth $\mathrm{J}$, et al. Hypothalamic dysfunction of the thrombospondin receptor alpha2delta-1 underlies the overeating and obesity triggered by brainderived neurotrophic factor deficiency. J Neurosci. (2014) 34:554-65. doi: 10.1523/JNEUROSCI.1572-13.2014

46. Del Campo JA, Gallego-Durán R, Gallego P, Grande L. Genetic and epigenetic regulation in nonalcoholic fatty liver disease (NAFLD). Int $J \mathrm{Mol}$ Sci. (2018) 19:E911. doi: 10.3390/ijms19030911

47. Mariani S, Fiore D, Basciani S, Persichetti A, Contini S, Lubrano C, et al. Plasma levels of SIRT1 associate with non-alcoholic fatty liver disease in obese patients. Endocrine (2015) 49:711-6. doi: 10.1007/s12020-014-0465-x

48. Mukhopadhyay P, Horváth B, Rajesh M, Varga ZV, Gariani K, Ryu D, et al. PARP inhibition protects against alcoholic and non-alcoholic steatohepatitis. J Hepatol. (2017) 66:589-600. doi: 10.1016/j.jhep.2016.10.023

49. Nawaz A, Mehmood A, Kanatani Y, Kado T, Igarashi Y, Takikawa A, et al. Sirtl activator induces proangiogenic genes in preadipocytes to rescue insulin resistance in diet-induced obese mice. Sci Rep. (2018) 8:11370. doi: 10.1038/s41598-018-29773-0

50. Kilic U, Gok O, Elibol-Can B, Ozgen IT, Erenberk U, Uysal O, et al. SIRT1 gene variants are related to risk of childhood obesity. Eur J Pediatr. (2015c) 174:473-9. doi: 10.1007/s00431-014-2424-1

51. Fujita N, Matsushita T, Ishida K, Topark-Ngarm A, Senawong T, Machado De Oliveira R, et al. Potential involvement of SIRT1 in the pathogenesis of osteoarthritis through the modulation of chondrocyte gene expressions. $J$ Orthop Res. (2011) 29:511-5. doi: 10.1002/jor.21284

52. Matsuzaki T, Matsushita T, Takayama K, Matsumoto T, Nishida K, Kuroda $\mathrm{R}$, et al. Disruption of Sirt1 in chondrocytes causes accelerated progression of osteoarthritis under mechanical stress and during ageing in mice. Ann Rheum Dis. (2014) 73:1397-404. doi: 10.1136/annrheumdis-2012-202620

53. Wang J, Gao JS, Chen JW Li F, Tian J. Effect of resveratrol on cartilage protection and apoptosis inhibition in experimental osteoarthritis of rabbit. Rheumatol Int. (2012) 32:1541-8. doi: 10.1007/s00296-010-1720-y

54. Li W, Cai L, Zhang Y, Cui L, Shen G. Intra-articular resveratrol injection prevents osteoarthritis progression in a mouse model by activating SIRT1 and thereby silencing HIF-2 $\alpha$. J Orthop Res. (2015) 33:1061-70. doi: 10.1002/jor.22859

55. Nishida K, Matsushita T, Takayama K, Tanaka T, Miyaji N, Ibaraki K, et al. Intraperitoneal injection of the SIRT1 activator SRT1720 attenuates the progression of experimental osteoarthritis in mice. Bone Joint Res. (2018) 7:252-62. doi: 10.1302/2046-3758.73.BJR-2017-0227.R1

56. Mercken EM, Hu J, Krzysik-Walker S, Wei M, Li Y, McBurney MW, et al. SIRT1 but not its increased expression is essential for lifespan extension in caloric-restricted mice. Aging Cell (2014) 13:193-6. doi: 10.1111/acel. 12151

57. Satoh A, Brace CS, Rensing N, Cliften P, Wozniak DF, Herzog ED, et al. Sirtl extends lifespan and delays aging in mice through the regulation of nk2 homeobox1 in the dmh and lh. Cell Metab. (2013) 18:416-30. doi: 10.1016/j.cmet.2013.07.013

58. Cantó C, Auwerx J. Caloric restriction, SIRT1 and longevity. Trends Endocrinol Metab. (2009) 20:325-31. doi: 10.1016/j.tem.2009.03.008

59. Cohen HY, Miller C, Bitterman KJ, Wall NR, Hekking B, Kessler B, et al. Calorie restriction promotes mammalian cell survival by inducing the SIRT1 deacetylase. Science (2004) 305:390-2. doi: 10.1126/science.1099196

60. Ungvari Z, Parrado-Fernandez C, Csiszar A, de Cabo R. Mechanisms underlying caloric restriction and lifespan regulation: implications for vascular aging. Circ Res. (2008) 102:519-28. doi: 10.1161/CIRCRESAHA.107.168369
61. Kilic U, Gok O, Bacaksiz A, Izmirli M, Elibol-Can B, Uysal O. SIRT1 gene polymorphisms affect the protein expression in cardiovascular diseases. PLoS ONE (2014) 9:e90428. doi: 10.1371/journal.pone.0090428

62. Kilic U, Gok O, Erenberk U, Dundaroz MR, Torun E, Kucukardali Y, et al. A remarkable age-related increase in SIRT1 protein expression against oxidative stress in elderly: SIRT1 gene variants and longevity in human. PLoS ONE (2015a) 10:e0117954. doi: 10.1371/journal.pone.0117954

63. Braidy N, Guillemin GJ, Mansour H, Chan-Ling T, Poljak A, Grant R. Age related changes in NAD+metabolism oxidative stress and Sirt1 activity in wistar rats. PLoS ONE (2011) 6:e19194. doi: 10.1371/journal.pone.0019194

64. Koltai E, Szabo Z, Atalay M, Bolodogh I, Naito H, Goto S, et al. Exercise alters SIRT1, SIRT6, NAD and NAMPT levels in skeletal muscle of aged rats. Mech Ageing Dev. (2010) 131:21-8. doi: 10.1016/j.mad.2009.11.002

65. Mills KF, Satoh A, Imai S. Age-associated loss of sirt1-mediated enhancement of glucose-stimulated insulin secretion in beta cellspecific sirt1-overexpressing (besto) mice. Aging Cell (2008) 7:78-88. doi: 10.1111/j.1474-9726.2007.00355.x

66. Cornelius C, Trovato Salinaro A, Scuto M, Fronte V, Cambria MT, Pennisi $M$, et al. Cellular stress response, sirtuins and UCP proteins in Alzheimer disease: role of vitagenes. Immun Ageing (2013) 10:41. doi: $10.1186 / 1742-4933-10-41$

67. Herskovits AZ, Guarente L. Sirtuin deacetylases in neurodegenerative diseases of aging. Cell Res. (2013) 23:746-58. doi: 10.1038/cr.2013.70

68. Patel NV, Gordon MN, Connor KE, Good RA, Engelman RW, Mason J, et al. Caloric restriction attenuates $\mathrm{A}$ beta-deposition in Alzheimer transgenic models. Neurobiol Aging (2005) 26:995-1000. doi: 10.1016/j.neurobiolaging.2004.09.014

69. Guarente L. Mitochondria-a nexus for aging, calorie restriction, and sirtuins? Cell (2008) 132:171-6. doi: 10.1016/j.cell.2008.01.007

70. Bonda DJ, Lee HG, Camins A, Pallàs M, Casadesus G, Smith MA, et al. The sirtuin pathway in ageing and Alzheimer disease: mechanistic and therapeutic considerations. Lancet Neurol. (2011) 10:275-9. doi: 10.1016/S1474-4422(11)70013-8

71. Rizzi L, Roriz-Cruz M. Sirtuin 1 and Alzheimer's disease: an up-to-date review. Neuropeptides (2018) 71:54-60 doi: 10.1016/j.npep.2018.07.001

72. Wencel PL, Lukiw WJ, Strosznajder JB, Strosznajder RP. Inhibition of Poly(ADP-ribose) polymerase-1 enhances gene expression of selected sirtuins and app cleaving enzymes in amyloid beta cytotoxicity. Mol Neurobiol. (2018) 55:4612-23. doi: 10.1007/s12035-017-0646-8

73. Chen J, Zhou Y, Mueller-Steiner S, Chen LF, Kwon H, Yi S, et al. SIRT1 protects against microglia-dependent amyloid-beta toxicity through inhibiting NF-kappaB signaling. J Biol Chem. (2005) 280:40364-74. doi: 10.1074/jbc.M509329200

74. Song JH, Yu JT, Liu M, Yan CZ, Tan L. Genetic association between ADAM10 gene polymorphism and Alzheimer's disease in a Northern Han Chinese population. Brain Res. (2011) 1421:78-81. doi: 10.1016/j.brainres.2011. 09.008

75. Xie J, Zhang X, Zhang L. Negative regulation of inflammation by SIRT1. Pharmacol Res. (2013) 67:60-7. doi: 10.1016/j.phrs.2012.10.010

76. Hardy J, Selkoe DJ. The amyloid hypothesis of Alzheimer's disease: progress and problems on the road to therapeutics. Science (2002) 297:353-6. doi: 10.1126/science.1072994

77. Qin W, Yang T, Ho L, Zhao Z, Wang J, Chen L, et al. Neuronal SIRT1 activation as a novel mechanism underlying the prevention of alzheimer disease amyloid neuropathology by calorie restriction. J Biol Chem. (2006) 281:21745-54. doi: 10.1074/jbc.M602909200

78. Serrano-Marco L, Chacón MR, Maymó-Masip E, Barroso E, Salvadó L, Wabitsch M, et al. TNF- $\alpha$ inhibits PPAR $\beta / \delta$ activity and SIRT1 expression through NF-kB in human adipocytes. Biochim Biophys Acta (2012) 1821:1177-85. doi: 10.1016/j.bbalip.2012.05.006

79. Vachharajani VT, Liu T, Wang X, Hoth JJ, Yoza BK, McCall CE. Sirtuins link inflammation and metabolism. J Immunol Res. (2016) 2016:8167273. doi: $10.1155 / 2016 / 8167273$

80. Kilic U, Elibol B, Uysal O, Kilic E, Yulug B, Sakul AS, et al. Specific alterations in the circulating levels of the SIRT1, TLR4, and IL7 proteins in patients with dementia. Exp Geront. (2018) 111:203-9. doi: 10.1016/j.exger.2018. 07.018 . 
81. Donmez G, Arun A, Chung CY, McLean PJ, Lindquist S, Guarente L. SIRT1 protects against alpha-synuclein aggregation by activating molecular chaperones. J Neurosci Off J Soc Neurosci. (2012) 32:124-32. doi: 10.1523/JNEUROSCI.3442-11.2012

82. Mudo G, Makela J, Di Liberto V, Tselykh TV, Olivieri M, Piepponen P, et al. Transgenic expression and activation of PGC-1alpha protect dopaminergic neurons in the MPTP mouse model of Parkinson's disease. Cell Mol Life Sci. (2012). 69:1153-65. doi: 10.1007/s00018-011-0850-Z

83. Pallàs M, Pizarro JG, Gutierrez-Cuesta J, Crespo-Biel N, Alvira D, Tajes M, et al. Modulation of SIRT1 expression in different neurodegenerative models and human pathologies. Neuroscience (2008) 154:1388-97. doi: 10.1016/j.neuroscience.2008.04.065

84. Araki T, Sasaki Y, Milbrandt J. Increased nuclear NAD biosynthesis and SIRT1 activation prevent axonal degeneration. Science (2004) 305:1010-3. doi: 10.1126/science.1098014

85. Bedalov A, Simon JA. Neuroscience. NAD to the rescue. Science (2004) 305:954-55. doi: 10.1126/science.1102497

86. Huang PS, Son JH, Abbott LC, Winzer-Serhan UH. Regulated expression of neuronal SIRT1 and related genes by aging and neuronal $\beta 2$ containing nicotinic cholinergic receptors. Neuroscience (2011) 196:189-202. doi: 10.1016/j.neuroscience.2011.09.007

87. Liu TF, Vachharajani VT, Yoza BK, McCall CE. NAD+-dependent sirtuin 1 and 6 proteins coordinate a switch from glucose to fatty acid oxidation during the acute inflammatory response. J Biol Chem. (2012) 287:25758-69. doi: 10.1074/jbc.M112.362343

88. Ciriello J, Tatomir A, Hewes D, Boodhoo D, Anselmo F, Rus V, et al. Phosphorylated SIRT1 as a biomarker of relapse and response to treatment with glatiramer acetate in multiple sclerosis. Exp Mol Pathol. (2018) 105:17580. doi: 10.1016/j.yexmp.2018.07.008

89. Kim D, Nguyen MD, Dobbin MM, Fischer A, Sananbenesi F, Rodgers JT, et al. SIRT1 deacetylase protects against neurodegeneration in models for Alzheimer's disease and amyotrophic lateral sclerosis. EMBO J. (2007) 26:3169-79. doi: 10.1038/sj.emboj.7601758

90. Tanno M, Kuno A, Yano T, Miura T, Hisahara S, Ishikawa S, et al. Induction of manganese superoxide dismutase by nuclear translocation and activation of SIRT1 promotes cell survival in chronic heart failure. $J$ Biol Chem. 285:8375-82. doi: 10.1074/jbc.M109.090266

91. Alcendor RR, Gao S, Zhai P, Zablocki D, Holle E, Yu X, et al. Sirt1 regulates aging and resistance to oxidative stress in the heart. Circ Res. (2007) 100:1512-21. doi: 10.1161/01.RES.0000267723.65696.4a

92. Hsu CP, Zhai P, Yamamoto T, Maejima Y, Matsushima S, Hariharan N, et al. Silent information regulator 1 protects the heart from ischemia/reperfusion. Circulation (2010) 122:2170-82. doi: 10.1161/CIRCULATIONAHA.110.958033

93. Teng FY, Tang BL. NF-kappaB signaling in neurite growth and neuronal survival. Rev Neurosci. (2010) 21:299-313. doi: 10.1515/REVNEURO.2010.21.4.299
94. Boyle EM Jr, Canty TG Jr, Morgan EN, Yun W, Pohlman TH Verrier ED. Treating myocardial ischemia-reperfusion injury by targeting endothelial cell transcription. Ann Thorac Surg. (1999) 68:1949-53. doi: 10.1016/S0003-4975(99)01033-4

95. Kamata H, Honda S, Maeda S, Chang L, Hirata H, Karin M. Reactive oxygen species promote TNFalpha-induced death and sustained JNK activation by inhibiting MAP kinase phosphatases. Cell (2005) 120:649-61. doi: $10.1016 /$ j.cell.2004.12.041

96. Matsukawa J, Matsuzawa A, Takeda K, Ichijo H. The ASK1-MAP kinase cascades in mammalian stress response. J Biochem. (2004) 136:261-5. doi: $10.1093 / \mathrm{jb} / \mathrm{mvh} 134$

97. Nasrin N, Kaushik VK, Fortier E, Wall D, Pearson KJ, de Cabo R, et al. JNK1 phosphorylates SIRT1 and promotes its enzymatic activity. PLoS ONE (2009) 4:e8414. doi: 10.1371/journal.pone.0008414

98. Tabuchi T, Satoh M, Itoh T, Nakamura M. MicroRNA-34a regulates the longevity-associated protein SIRT1 in coronary artery disease: effect of statins on SIRT1 and microRNA-34a expression. Clin Sci (Lond.) (2012) 123:161-71. doi: 10.1042/CS20110563

99. Kok SH, Lin LD, Hou KL, Hong CY, Chang CC, Hsiao M, et al. Simvastatin inhibits cysteine-rich protein 61 expression in rheumatoid arthritis synovial fibroblasts through the regulation of sirtuin-1/FoxO3a signaling. Arthr Rheum. (2013) 65:639-49. doi: 10.1002/art.37807

100. Kilic U, Gok O, Elibol-Can B, Uysal O, Bacaksiz A. Efficacy of statins on sirtuin 1 and endothelial nitric oxide synthase expression: the role of sirtuin 1 gene variants in human coronary atherosclerosis. Clin Exp Pharmacol Physiol. (2015b) 42:321-30. doi: 10.1111/1440-1681. 12362

101. Yano M, Matsumura T, Senokuchi T, Ishii N, Murata Y, Taketa K, et al. Statins activate peroxisome proliferator-activated receptor gamma through extracellular signal-regulated kinase $1 / 2$ and p38 mitogen-activated protein kinase-dependent cyclooxygenase-2 expression in macrophages. Circ Res. (2007) 100:1442-51. doi: 10.1161/01.RES.0000268411.49 $545.9 \mathrm{c}$

102. Han L, Zhou R, Niu J, McNutt MA, Wang P, Tong T. SIRT1 is regulated by a PPAR $\gamma$-SIRT1 negative feedback loop associated with senescence. Nucleic Acids Res. (2010) 38:7458-71. doi: 10.1093/nar/gkq609

Conflict of Interest Statement: The authors declare that the research was conducted in the absence of any commercial or financial relationships that could be construed as a potential conflict of interest.

Copyright (c) 2018 Elibol and Kilic. This is an open-access article distributed under the terms of the Creative Commons Attribution License (CC BY). The use, distribution or reproduction in other forums is permitted, provided the original author(s) and the copyright owner(s) are credited and that the original publication in this journal is cited, in accordance with accepted academic practice. No use, distribution or reproduction is permitted which does not comply with these terms. 